\title{
Teste acelerado de argamassas e a combinação de adições minerais ativas com agregado potencialmente reativo
}

\author{
Cleberson S. Adorno ${ }^{a}$, Eloise A. Langaro ${ }^{a}$, Marcelo H. F. Medeiros ${ }^{a}$, Andressa Gobbi \\ ${ }^{a}$ Universidade Federal do Paraná, Departamento de Construção Civil, Curitiba, Brasil.

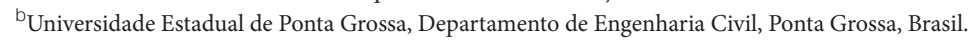

\section{Informações}

Recebido 15 Junho 2020

Manuscrito revisado recebido

2 Agosto 2020

Aceito 8 Agosto 2020

Palavras-chave

AMBT

Cinza de casca de arroz

Expansão

Porosimetria

\section{Resumo}

O teste acelerado de barras de argamassa (AMBT) é o mais rápido para detectar a reatividade de agregados. Porém, apresenta diversas limitações quanto à classificação, limites determinados e as condições de aceleração do ensaio. Quando se trata do AMBT para classificar adições minerais potencialmente inibidoras da RAS, a solução de $\mathrm{NaOH}$ e a alta temperatura são fatores cruciais. $\mathrm{O}$ presente trabalho visa investigar o efeito do AMBT no desenvolvimento da RAS em combinações de cimento com cinza de casca de arroz e sílica ativa. A expansão induzida foi usada para avaliar a cinética da RAS. Além disso, as propriedades químicas e físicas da matriz hidratada em condições normais de temperatura e umidade e em condições do ensaio foram caracterizadas por DRX, TGA e MIP. A finura e o tamanho das partículas da cinza de casca de arroz foram determinantes na mitigação da RAS. As condições do AMBT são agressivas demais para descartar um material apenas pelos resultados de expansão. Os mecanismos de atuação das adições minerais frente a RAS devem ser mais bem entendidos e avaliados perante o uso de ensaios que não comprometam seu desenvolvimento.

\section{Accelerated test of mortars}

\section{Article info}

Received 15 June 2020

Received in revised form 2 August 2020

Accepted 8 August 2020

\section{Keywords}

AMBT

Rice husk ash

Expansion

Porosimetry

\begin{abstract}
The accelerated test of mortar bars (AMBT) is the fastest to detect the reactivity of aggregates. However, it presents several limitations regarding the classification, limits and the conditions to accelerate the test. When AMBT is used to classify mineral additions that potentially inhibit RAS, $\mathrm{NaOH}$ solution and high temperature are crucial factors. The present work aims to investigate the effect of AMBT on the development of RAS in combinations of cement with rice husk ash and silica fume. The induced expansion was used to assess the kinetics of RAS. In addition, the chemical and physical properties of the hydrated matrix under normal conditions of temperature and humidity and under test conditions were characterized by XRD, TGA and MIP. The fineness and particle size of rice husk ash were determinant in the mitigation of RAS. AMBT conditions are too aggressive to discard a material just by the determination of expansion. The mechanisms of action of mineral additions subjected to RAS must be better understood and evaluated by using tests that do not compromise their development.
\end{abstract}

\section{Ensayo acelerado de morteros}

\section{Información}

Recibido 15 Juni 2020

Manuscrito revisado recibido 2 Agosto 2020

Aceptado 8 Agosto 2020

\section{Palabras clave}

AMBT

Ceniza de cáscara de arroz

Expansion

Porosimetria

\section{Resumen}

El ensayo acelerado de barras de mortero (AMBT) es lo más rápido para detectar la reactividad de áridos. Sin embargo, presenta varias limitaciones cuanto a la clasificación, los límites determinados y las condiciones para acelerar el ensayo. Cuando se usa el AMBT para clasificar adiciones minerales potencialmente inhibidoras de la RAS, la solución de $\mathrm{NaOH}$ y las altas temperaturas son factores cruciales. El presente trabajo tiene como objetivo investigar el efecto del AMBT en el desarrollo de la RAS en mezclas de cemento con ceniza de cáscara de arroz y humo de sílice. La expansión inducida se utilizó para evaluar la cinética de la RAS. Las propiedades químicas y físicas de la matriz hidratada en condiciones normales de temperatura y humedad y en condiciones de ensayo se caracterizaron por DRX, TGA y MIP. La finura y el tamaño de partícula de la ceniza fueron determinantes para mitigar la RAS. Las condiciones del AMBT son demasiado agresivas para descartar un material solamente por la determinación de la expansión. Los mecanismos de acción de las adiciones minerales frente a la RAS deben entenderse y evaluarse mejor antes de utilizar pruebas que no comprometan su desarrollo.

\footnotetext{
* Autor correspondente em: Universidade Estadual de Ponta Grossa, Departamento de Engenharia Civil, Ponta Grossa, Brasil.

E-mail: agobbi@uepg.br (A. Gobbi)
}

https://doi.org/10.47842/juts.v3i1.23

ISSN: 2675-780X 


\section{Introdução}

A durabilidade relacionada ao tempo de vida útil das estruturas de concreto armado é fator preponderante nas construções atuais. A observância de aspectos relativos à escolha dos materiais, de acordo com o local de inserção da nova estrutura, deve ser considerada como ponto de partida para garantia da durabilidade. Manifestações patológicas como a reação álcalisílica (RAS) decorrem da escolha incorreta de materiais e do uso de agregados potencialmente reativos em ambientes propícios a ocorrência. Uma simples avaliação preliminar das condições e dos agregados pode evitar danos futuros que por muitas vezes se tornam irreparáveis.

Ensaios normatizados, como os previstos na NBR 15577 (2018), ASTM C 1260 (2014), CAN/ CSA A-23.2-25A-14 (2014), UNE 146508 (2018) e em outros países, já conseguem antecipar, antes do lançamento da construção, que o agregado a ser utilizado no concreto tem potencial reativo para desencadear uma reação deletéria. E um dos ensaios amplamente discutidos na comunidade científica, é o teste acelerado das barras de argamassa, conhecido como AMBT Accelerated Mortar Bar Test. Ele é reconhecido por apresentar resultados rápidos para classificação dos agregados, geralmente em torno de 14 até 30 dias. Porém devido as suas condições severas de aplicação, temperatura elevada $\left(80{ }^{\circ} \mathrm{C}\right)$ e o uso de solução altamente alcalina (uso de $\mathrm{NaOH}$ ), tem sido bastante criticado por diversos autores (FOURNIER e BÉRUBÉ, 2000; THOMAS et al., 2006; ALAEJOS et al., 2014; LATIFEE e RANGARAJU, 2015; GOLMAKANI E HOOTON, 2016; DESCHENES E MICAH HALE, 2017).

As críticas em torno do AMBT são de classificações errôneas, com resultados falso positivos e falso negativos, que podem ser gerados com o método. Certos tipos de agregados tem uma reação lenta ao longo do tempo tornando alguns resultados incorretos, ou seja, falsos-negativos (aqueles agregados que se mostram inofensivos, mas ao longo do tempo mostram potencial reativo). Além disso, podem ocorrer também os falsos positivos, aqueles cujo resultado descarta o uso do agregado, mas poderiam ser utilizados sem problemas nos elementos de concreto (FOURNIER et al., 2006). O teste é severo demais para agregados com boa performance sendo não recomendando para rejeitação, e sim apenas para aceitação (FOURNIER e BÉRUBÉ, 2000; LINDGARD et al., 2012).

Combinações entre materiais como pozolanas, e agregados reativos também podem ser testados a partir do AMBT. A mesma metodologia e limites de expansão são aplicados com o intuito de classificar se o material tem capacidade de inibir a reação álcali-agregado. Nenhum ajuste foi feito por parte das normas com relação a essa classificação.

É reconhecido que as fases amorfas das adições minerais ativas podem reagir $\mathrm{com} \mathrm{Ca}(\mathrm{OH})_{2}$ e formar produtos hidratados pozolânicos, como o C-S-H, reduzindo a quantidade de hidróxidos e $\mathrm{o} \mathrm{pH}$ da solução de poros do concreto, sendo capaz de limitar a ocorrência de reação álcali-sílica (AQUINO et al., 2001; HASPARYK et al., 2001; THOMAS, 2011). Porém, quando o AMBT é usado para avaliar as adições neste contexto, as condições relativas à solução alcalina de hidróxido de sódio e a temperatura elevada $\left(80^{\circ} \mathrm{C}\right)$ tornam-se cruciais no desempenho dos materiais. A fonte de álcalis externa é inesgotável e, portanto, muitas adições ativas conseguem apenas reduzir a penetração da solução temporiariamente, retardando a ocorrência da reação e a taxa de expansão (THOMAS et al., 2007).

Apesar da elevada temperatura propiciar a aceleração da reação pozolânica das adições minerais ativas, entender os mecanismos por traz dessa aceleração se faz necessária, uma vez que adições consideradas altamente reativas, como é o caso da cinza de casca de arroz, muitas vezes não consegue mitigar a expansão ocasionada pela RAS (AHSAN e HOSSAIN, 2018).

Neste contexto, o objetivo desta pesquisa foi avaliar o teste acelerado de barras de argamassa perante o uso da combinação de um agregado potencialmente reativo e adições minerais ativas como a sílica ativa e a cinza de casca de arroz. Modificações da microestrutura dos materiais nas condições do AMBT (solução de $\mathrm{NaOH}$ e temperatura elevada) foram comparadas a 
condições normais de umidade e temperatura para desenvolvimento da argamassa. Difração de raios- $X$, termogravimetria e porosimetria por intrusão de mercúrio foram utilizados para analisar os mecanismos físicos e químicos das adições no desempenho frente a reação álcali-sílica.

\section{Programa experimental}

\subsection{Materiais}

Foi utilizado cimento Portland, do tipo CPVARI, como referência desse estudo, em razão da ausência de adições minerais ativas em sua composição. O CPV-ARI é equivalente ao cimento tipo III, cimento Portland de alta resistência inicial, de acordo com a ASTM C150 e tipo I, com classe R de resistência à compressão, segundo a EN 197-1. A Tabela 1 apresenta as caracteristicas químicas e físicas do cimento.

A cinza de casca de arroz (CCA) proveniente da queima controlada em leito fluidilizado e a sílica ativa (SA) usadas neste experimento apresentaram massa específica de $2,12 \mathrm{~g} / \mathrm{cm}^{3}$ e $2,18 \mathrm{~g} / \mathrm{cm}^{3}$, respectivamente.

A curva granulométrica dos materiais está apresentada na Figura 1(A) e foi obtida utilizando um granulômetro a laser via úmido. É possível observar

Tabela 1. Propriedades químicas e físicas do cimento.

\begin{tabular}{cc}
\hline Propriedade & Resultado \\
\hline $\mathrm{CaO}$ & 59,36 \\
$\mathrm{SiO}_{2}$ & 16,27 \\
$\mathrm{Al}_{2} \mathrm{O}_{3}$ & 5,06 \\
$\mathrm{SO}_{3}$ & 5,30 \\
$\mathrm{Fe}_{2} \mathrm{O}_{3}$ & 2,77 \\
$\mathrm{MgO}$ & 4,63 \\
$\mathrm{~K}_{2} \mathrm{O}$ & 1,06 \\
$\mathrm{Na}_{2} \mathrm{O}_{\text {eq }}$ & 0,697 \\
$\mathrm{CaOlivre}$ & 1,46 \\
Resíduo insolúvel $(\%)$ & 0,67 \\
Perda ao fogo $(\%)$ & 3,43 \\
Finura Blaine $\left(\mathrm{cm}^{2} / \mathrm{g}\right)$ & 4510 \\
Finura BET $\left(\mathrm{cm}^{2} / \mathrm{g}\right)$ & 1,070 \\
Massa específica $\left(\mathrm{g} / \mathrm{cm}^{3}\right)$ & 3,13 \\
\hline
\end{tabular}

na Figura 1(B) os pontos que correspondem aos tamanhos de partícula 50 (diâmetro médio) e $90 \%$ sobre a distribuição cumulativa. A sílica ativa apresentou $D_{50}=0,25 \mu \mathrm{m} \mathrm{e} D_{90}=2,0 \mathrm{\mu m}$, inferiores aos demais materiais, seguido do cimento e da cinza de casca de arroz.

A Tabela 2 mostra a análise química das adições minerais (realizada por fluorescência de raios-X), assim como o equivalente alcalino, a área superficial específica (BET) e a perda ao fogo (LOI). $\mathrm{Na}$ constituição de ambas as adições ativas há predominância de sílica e pequenas quantidades de outros elementos como alumina, anidrido sulfúrico, óxido de ferro e cal. O carbono (LOI) e potássio (álcalis) se apresentam em quantidades ligeiramente superiores na CCA. Quando se trata de reação álcali-sílica, a quantidade de carbono e o equivalente alcalino podem contribuir negativamente para o controle da expansão (SHEHATA e THOMAS, 2000). A cinza de casca de arroz atende o limite estabelecido pela ASTM C618, que regula o uso de cinzas em concreto, quanto a especificação de LOI, que é $6 \%$.

A reatividade da cinza de casca de arroz é regulada principalmente pela quantidade de sílica amorfa disponível para a reação pozolânica. Dessa forma, a presença de fases cristalinas impacta de forma negativa na pozolanicidade da adição. As fases mineralógicas da cinza de casca de arroz e da sílica ativa foram identificadas por difratometria de raios-X, em equipamento Rigaku modelo Ultima IV. A análise foi realizada entre 5 e $75^{\circ} 2 \theta$, com passo angular de $0,02{ }^{\circ} 2 \theta$ e tempo por passo de 1 segundo. O difratograma da cinza de casca de arroz é mostrado na Figura 2.

O difratograma caracteriza uma estrutura amorfa na cinza de casca de arroz contendo apenas uma pequena parcela organizada como cristobalita, que é uma forma polimórfica do dióxido de silício. No difratograma da sílica ativa não foram observados picos característicos, mostrando uma estrutura predominantemente amorfa (Figura 3).

A capacidade das adições ativas em fixar cal por atividade pozolânica, foi determinada pelo ensaio Chapelle modificado. No Brasil, o método Capelle modificado é normalizado de acordo com 

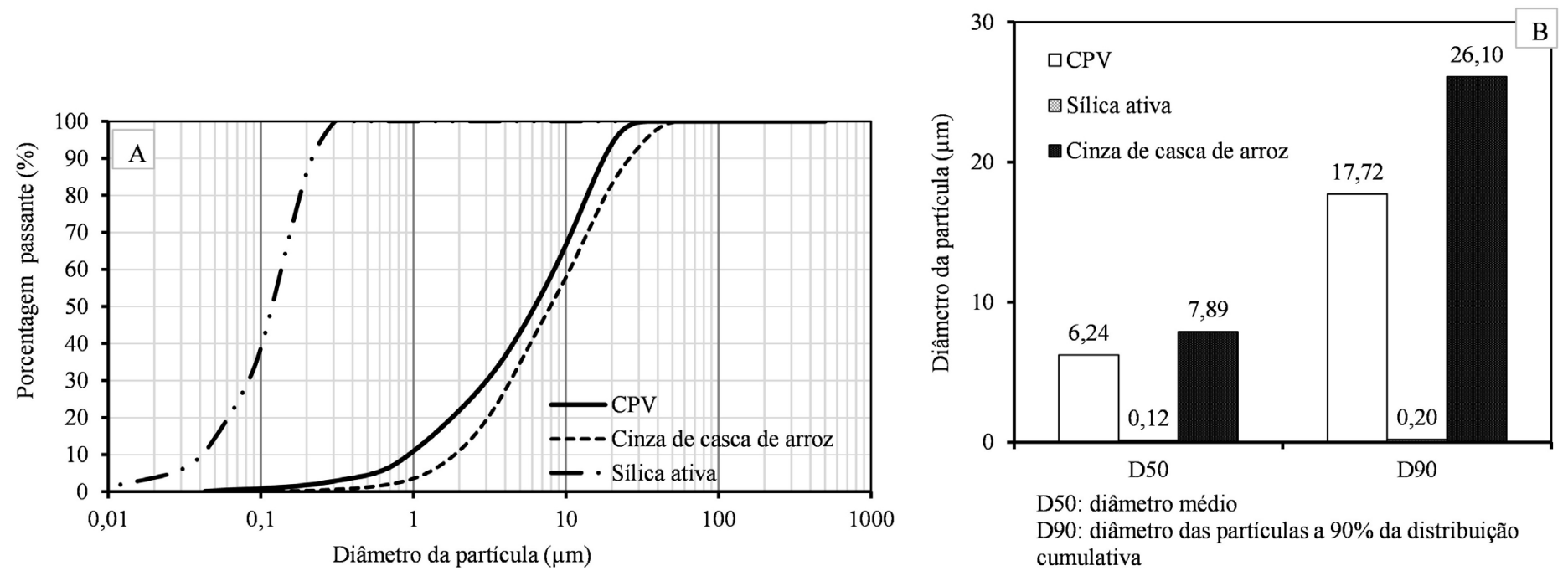

Fig. 1. Distribuição granulométrica dos materiais.

a NBR 15895. Segundo Quarcioni et al. (2015), esse método foi originalmente proposto por estudos de Raverdy et al. (1980), e é um método direto para a determinação da reatividade pozolânica de diferentes materiais. Este ensaio consiste, basicamente, em manter sob agitação, por um período de (16 \pm 2 ) horas, à temperatura de (90 $\pm 5{ }^{\circ} \mathrm{C}$, uma mistura de $1,0 \mathrm{~g}$ de adição mineral e 2,0 g de óxido de cálcio ( $\mathrm{CaO}$ ) em $250 \mathrm{~mL}$ de água, acondicionada em Erlenmeyer polimérico. Os resultados são obtidos por titulação e expressos pela quantidade de hidróxido de cálcio fixado por g de adição. O consumo de $330 \mathrm{~g} \mathrm{CaO/g}$ de adição corresponde a $436 \mathrm{mg} \mathrm{Ca}(\mathrm{OH})_{2} / \mathrm{g}$, que é o limite estabelecido para classificar uma adição como pozolânica.

A cinza de casca de arroz apresentou elevada

Tabela 2. Propriedades químicas e físicas das adições minerais.

\begin{tabular}{ccc}
\hline Propriedade & CCA & SA \\
\hline $\mathrm{CaO}$ & 0,43 & 0,19 \\
$\mathrm{SiO}_{2}$ & 88,47 & 92,35 \\
$\mathrm{Al}_{2} \mathrm{O}_{3}$ & 2,72 & 2,21 \\
$\mathrm{SO}_{3}$ & 1,55 & 1,52 \\
$\mathrm{Fe}_{2} \mathrm{O}_{3}$ & 0,05 & 0,05 \\
$\mathrm{MgO}_{\mathrm{K}} \mathrm{O}$ & - & - \\
$\mathrm{Na}_{2} \mathrm{O}_{\text {ea }}$ & 1,46 & 0,94 \\
Outros óxidos & 0,961 & 0,619 \\
Perda ao fogo (\%) & 0,49 & 0,04 \\
Finura BET (cm $/ \mathrm{g})$ & 4,84 & 2,70 \\
\hline
\end{tabular}

capacidade em fixar cal, resultando em 1336 mg $\mathrm{Ca}(\mathrm{OH})_{2} / \mathrm{g}$ de pozolana, valor próximo ao da sílica ativa, $1542 \mathrm{mg} \mathrm{Ca}(\mathrm{OH})_{2} / \mathrm{g}$. Esses resultados são superiores ao limite de classificação que é 436 mg $\mathrm{Ca}(\mathrm{OH})_{2} / \mathrm{g}$ de pozolana.

O agregado reativo utilizado foi obtido na região de Curitiba (Brasil), escolhido por ter histórico de manifestações patológicas diagnosticadas como reação álcali-agregado em obras hidráulicas nacionais (VALDUGA, 2007). O agregado é classificado como feldspato de potássio (ASTM C 294: 2017) devido à sua composição química indicar picos característicos de sanidina e albita (Figura 4). A composição química do agregado, obtida por fluorescência de raios-X, é constituída de $\mathrm{SiO}_{2}(63,5 \%), \mathrm{Al}_{2} \mathrm{O}_{3}(15,1 \%), \mathrm{Fe}_{2} \mathrm{O}_{3}(7,0 \%), \mathrm{K}_{2} \mathrm{O}$ (6,6\%), $\mathrm{Na}_{2} \mathrm{O}(4,4 \%)$ e $\mathrm{CaO}(2,1 \%)$, e outros óxidos com porcentagem abaixo de 0,5\%. 0 alto teor de potássio pode contribuir para a liberaração de quantidades significativas de álcalis na solução de poros do concreto. Em condições normais, a liberação de álcalis acelera significativamente o processo de deterioração do concreto (CONSTANTINER e DIAMOND, 2003; LOCATI et al., 2010).

\subsection{Proporções das misturas e teste acelerado das barras de argamassa}

As proporções das misturas consideram substituição parcial do cimento Portland, em massa, pelas adições de sílica ativa e cinza de casca de arroz, em um teor de $10 \%$. O traço utilizado da mistura de 


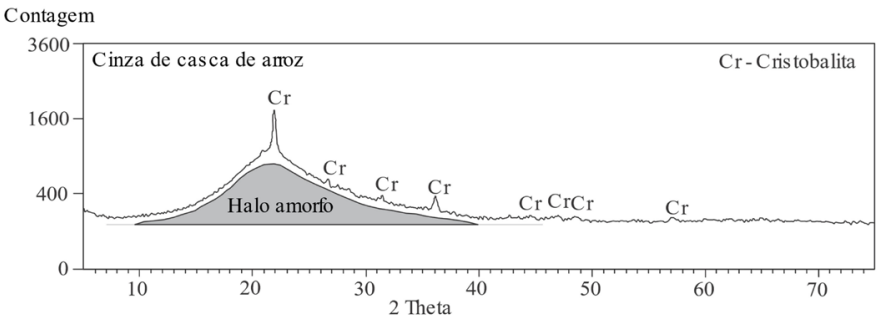

Fig. 2. Difratograma da cinza de casca de arroz.

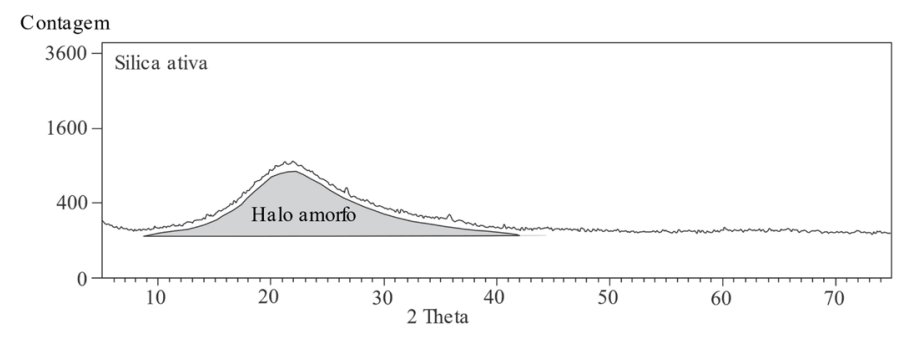

Fig. 3. Difratograma da sílica ativa.

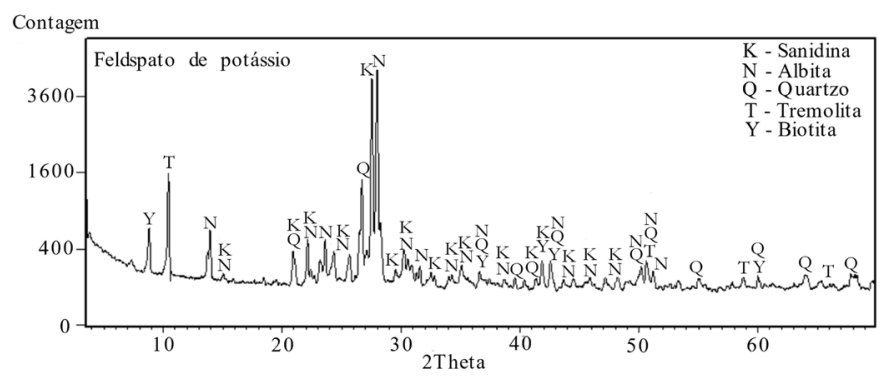

Fig. 4. Difratograma da sílica ativa.

referência, de acordo com NBR 15577:2018 parte 4 e 5, foi 1:2,25:0,47 (cimento: agregado miúdo: relação água/aglomerante). O agregado reativo foi inicialmente preparado utilizando o moinho de bolas Los Angeles e posteriormente dividido nas frações granulométricas requeridas pela norma.

Foram moldados 6 corpos de prova prismáticos para cada série, nas dimensões de 2,5 × 2,5 × 28,5 $\mathrm{cm}$. Após a moldagem, todos os corpos de prova foram submetidos a cura em câmara úmida por 24 horas. E, após a desmoldagem, 3 corpos de prova de cada série foram submetidos as condições especificadas pela norma, $24 \mathrm{~h}$ em água a $80 \pm$ $2{ }^{\circ} \mathrm{C}$ e posterior imersão em solução de hidróxido de sódio $(\mathrm{NaOH}-1 \mathrm{~N})$ a $(80 \pm 2){ }^{\circ} \mathrm{C}$ durante 30 dias; e os outros 3 (grupo de controle em água destilada) foram mantidos em água destilada em temperatura ambiente (aproximadamente $24^{\circ} \mathrm{C}$ ). $\mathrm{O}$ segundo grupo, imerso apenas em água destilada, foi moldado com a finalidade de observar as diferenças microestruturais que o ensaio acelerado de barras de argamassa provoca.

As leituras de expansão nas barras foram realizadas em 24 horas (inicial) e duas vezes por semana, durante todo o período do ensaio. A expansão induzida foi medida comparando-se a medida inicial e a medida realizada ao longo do período de exposição.

\subsection{Análise da microestrutura}

Análises das mudanças na microestrutura das barras por difração de raios-X (DRX), termogravimetria (TG/DTG) e porosimetria por intrusão de mercúrio (MIP) foram realizadas. Essas análises tiveram o intuito de entender as transformações da microestrutura devido a ação da RAS, adições minerais ativas e também do teste acelerado. Após o período de expansão das barras (30 dias), todas as amostras de ambos os grupos (em solução e controle) foram fragmentadas e imergidas em álcool etílico p.a. por 24 horas para secagem e interrupção do processo de hidratação. Em seguida, os fragmentos foram colocados em estufa a $40{ }^{\circ} \mathrm{C}$ por mais 24 horas para completar o processo.

Após o período de secagem em estufa a $40{ }^{\circ} \mathrm{C}$, as amostras foram finamente moídas (<44Nm) para realização do ensaio de DRX e de termogravimetria. Para a difração de raios- $X$, foi utilizada a faixa de varredura de 3,5 a $70{ }^{\circ} 2 \theta$, com passo angular de 0,017 20 e tempo de $10,16 \mathrm{~s}$ por passo, utilizando o difratômetro PANALYTICAL modelo EMPYREAN detector X'Celerator. Para a análise termogravimétrica (TG/DTG) foi utilizado o equipamento da TA Instruments modelo SDT 2960, em atmosfera dinâmica de nitrogênio $\left(\mathrm{N}_{2}\right)$ e fluxo de $100 \mathrm{~mL} / \mathrm{min}$. As amostras já finamente moídas (<44 jm), foram colocadas em um cadinho de alumina, como porta amostra, e seguiram para a realização do ensaio. A taxa de aquecimento foi de $10{ }^{\circ} \mathrm{C} / \mathrm{min}$., aplicada até $1200{ }^{\circ} \mathrm{C}$.

Para a análise de porosimetria por intrusão de mercúrio foram utilizados os fragmentos das barras de argamassa, os quais foram secos em estufa a uma temperatura média de $100{ }^{\circ} \mathrm{C}$ por 24 horas. Após o resfriamento à temperatura ambiente, as 
amostras foram colocadas em um porta amostra com mercúrio. O princípio da metodologia para a análise consistiu em medir o volume de intrusão de mercúrio por grama de amostra ( $\mathrm{mL} / \mathrm{g})$, característico de cada pressão aplicada (inicial pressão de 1,5 psi a 30 psi; alta pressão - de 30 psi a 61000 psi), possibilitando expressar este volume em função do diâmetro dos poros.

Com base nos valores de porosidade total, existem teorias que definem o cálculo da permeabilidade absoluta a partir das propriedades mensuráveis do sistema cimentício, como porosidade $(\varphi)$, diâmetro médio dos poros $(d)$ e tortuosidade $(\tau)$, por exemplo. Katz e Thompson em 1986, baseados na lei de Darcy, propuseram um modelo para o cálculo da permeabilidade que relaciona a condutividade no material $(\sigma)$ com a condutividade do espaço poroso do mesmo $\left(\sigma_{0}\right)$, comprimento característico do espaço dos poros $\left(I_{c}\right)$ e uma constante de permeabilidade $c=0,0042$ (KATZ e THOMPSON, 1986). A permeabilidade absoluta calculada está descrita na Equação. 1. O equipamento de medição se baseia neste modelo para o cálculo da permeabilidade.

$$
k=c * l c^{2} \frac{\sigma}{\sigma_{0}}
$$

\section{Resultados e discussões}

\subsection{Teste acelerado em barras de argamassa (AMBT)}

Para o teste acelerado das barras de argamassa o limite de expansão da NBR 15577-1 que indica se um agregado pode ser classificado como "seguro", é estabelecido como a expansão total menor que 0,19\% aos 30 dias de exposição. Esse mesmo limite se aplica ao material inibidor da reação, no caso das pozolanas.

Os resultados da expansão das barras de argamassa submetidas as condições do AMBT estão apresentadas na Figura 5.

É possível observar que a argamassa de referência não ultrapassou o limite de expansão estipulado pela norma (0,19\%) no período de análise (30 dias). Isso indica que o agregado não apresentou potencial reativo nesse ensaio. Quanto ao uso das adições minerais, observa-se que ambas exibiram certa capacidade de minimização da expansão ocasionada pela RAS. Porém, a adição de cinza de casca de arroz apresentou menor potencial mitigador quando comparada a argamassa com sílica ativa.

Os resultados obtidos para a expansão das barras de argamassa foram validados utilizando análise estatística. A Análise de Variância (ANOVA) oneway com Teste de comparação múltipla de Tukey, considerando um intervalo de confiança de 95\%, indicou haver diferença estatística significativa na expansão entre todas as séries de barras analisadas na idade de 30 dias (Figura 6).

Apesar da cinza de casca de arroz ser considerada uma adição de alta reatividade, apresentando elevada capacidade de fixar cal no resultado do teste de Chapelle modificado (1336 mg $\mathrm{Ca}(\mathrm{OH})_{2} / \mathrm{g}$ de pozolana), alguns fatores relacionados ao material, como composição química e finura, podem ter

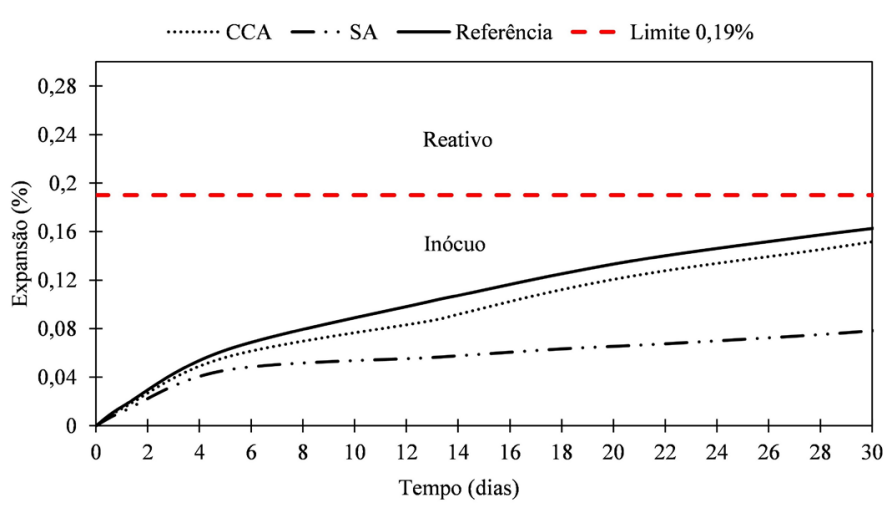

Fig. 5. Evolução da expansão das barras de argamassa.

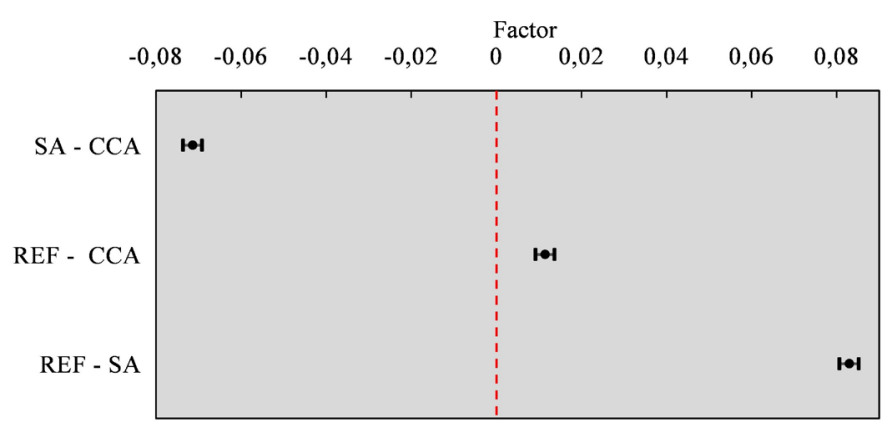

Fig. 6. Análise comparative de Tukey das amostras submetidas ao ensaio AMBT, aos 30 dias. 
contribuído negativamente para seu desempenho. A pequena diferença entre a expansão das barras de referência e das com CCA indicam que seus mecanismos não foram suficientes para inibir a reação ao nível da sílica ativa. Em contrapartida as condições do teste acelerado, temperatura elevada $\left(80{ }^{\circ} \mathrm{C}\right)$ e solução agressiva $(\mathrm{NaOH} 1 \mathrm{~N})$, podem ter dificultado o efeito positivo da atividade pozolânica desenvolvida por esta adição.

Quando é observada apenas a barra de referência, o resultado de expansão total não ultrapassa o limite estabelecido pela NBR 15577, o que confere ao teste a aos limites estabelecidos uma certa incerteza uma vez que este agregado já foi diagnosticado como reativo devido a fissuras, características da RAA, causadas em uma obra de barragem no Brasil.

O ensaio AMBT tem sido criticado em vários trabalhos (FOURNIER e BÉRUBÉ, 2000; THOMAS et al., 2006; GOLMAKANI e HOOTON, 2016; DESCHENES e MICAH HALE, 2017) por apresentar tendência a "falso positivo" e "falso negativo". Um exemplio é que alguns agregados podem apresentar o desenvolvimento da RAS mais lento, sugerindo assim que os limites propostos pelas normas são inadequados (ALAEJOS et al., 2014). Latifee e Rangaraju (2015) apontam as limitações do teste AMBT em sua pesquisa e, comentam que a questão da moagem excessiva dos agregados e o uso de temperatura elevada no teste podem alterar a reatividade dos agregados e das adições, o que prejudica o resultado final do ensaio.

É reconhecido, portanto, que o teste acelerado em argamassas não é o mais indicado para classificar um agregado como reativo ou um material como inibidor da RAS. Limites distintos em diferentes normas são apontados e, apesar de agregados diferentes serem encontrados em cada região do mundo, é aconselhável que testes em concreto e principalmente em campo sejam realizados.

\subsection{Difração de raios- $X$}

O difratograma da série de referência com cimento Portland CPV-ARI, coletado após o período de ensaio de expansão, é apresentado na Figura 7. Os compostos identificados são referentes a argamassa, ou seja, contém também componentes presentes do agregado utilizado. A intensidade dos picos foi normalizada. No difratograma é possível observar a influência da solução de $\mathrm{NaOH} 1 \mathrm{~N}$ e da temperatura a $80^{\circ} \mathrm{C}$ nos compostos das amostras submetidas ao ensaio AMBT e compará-los aos compostos formados nas argamassas mantidas em água destilada.
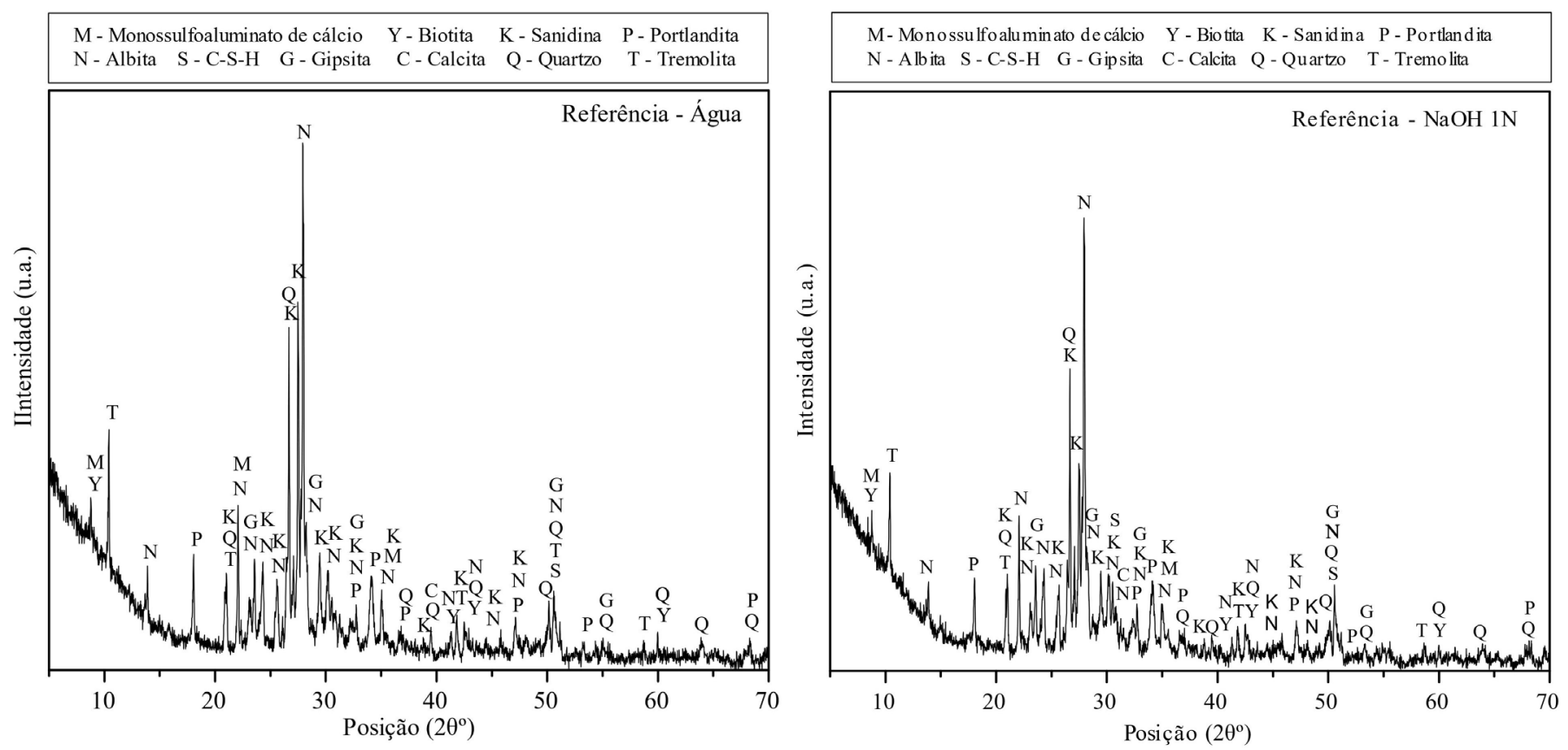

Fig. 7. Difratograma da série de referência em água destilada e solução de $\mathrm{NaOH} 1 \mathrm{~N}$. 

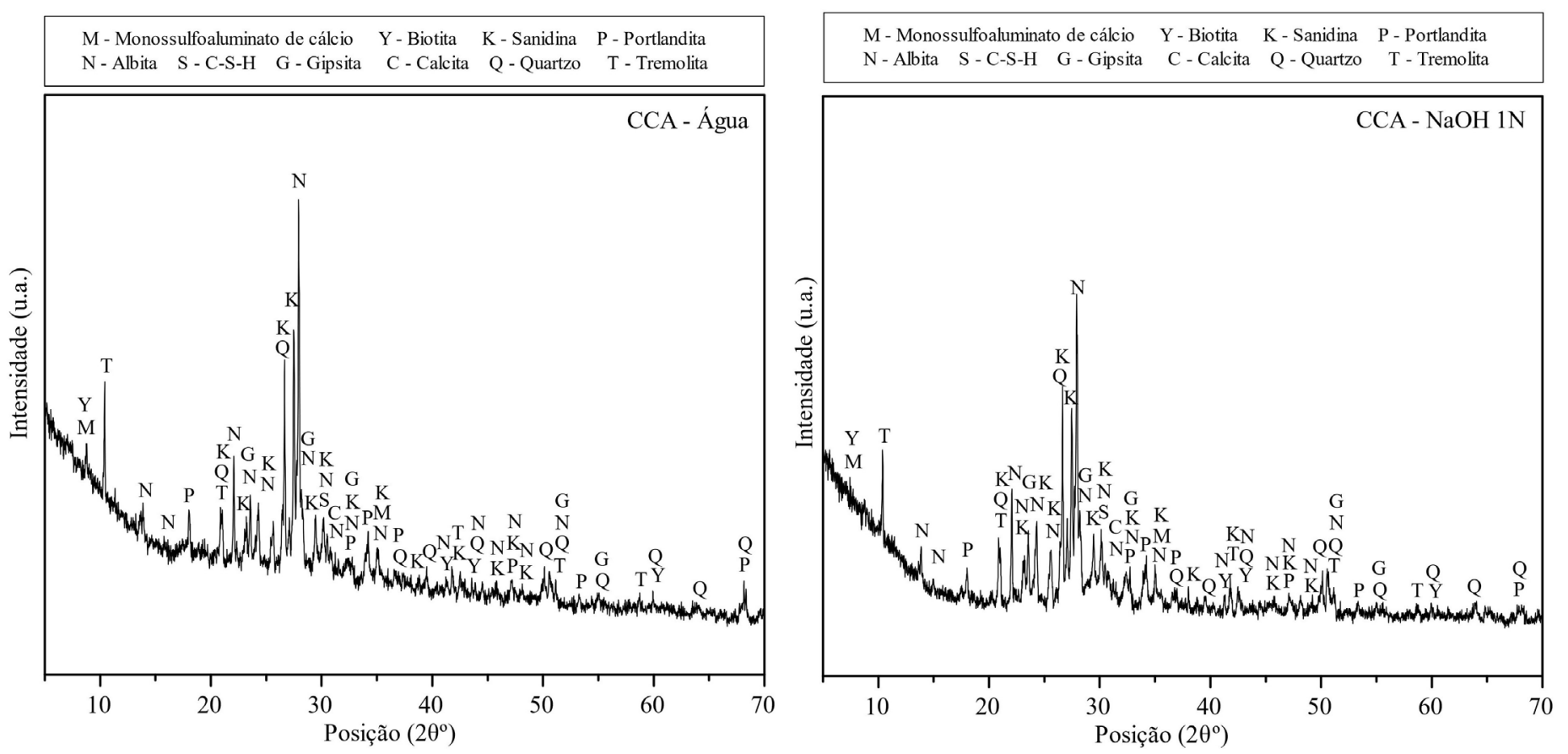

Fig. 8. Difratograma da série com cinza de casca de arroz em água destilada e solução de $\mathrm{NaOH} 1 \mathrm{~N}$.
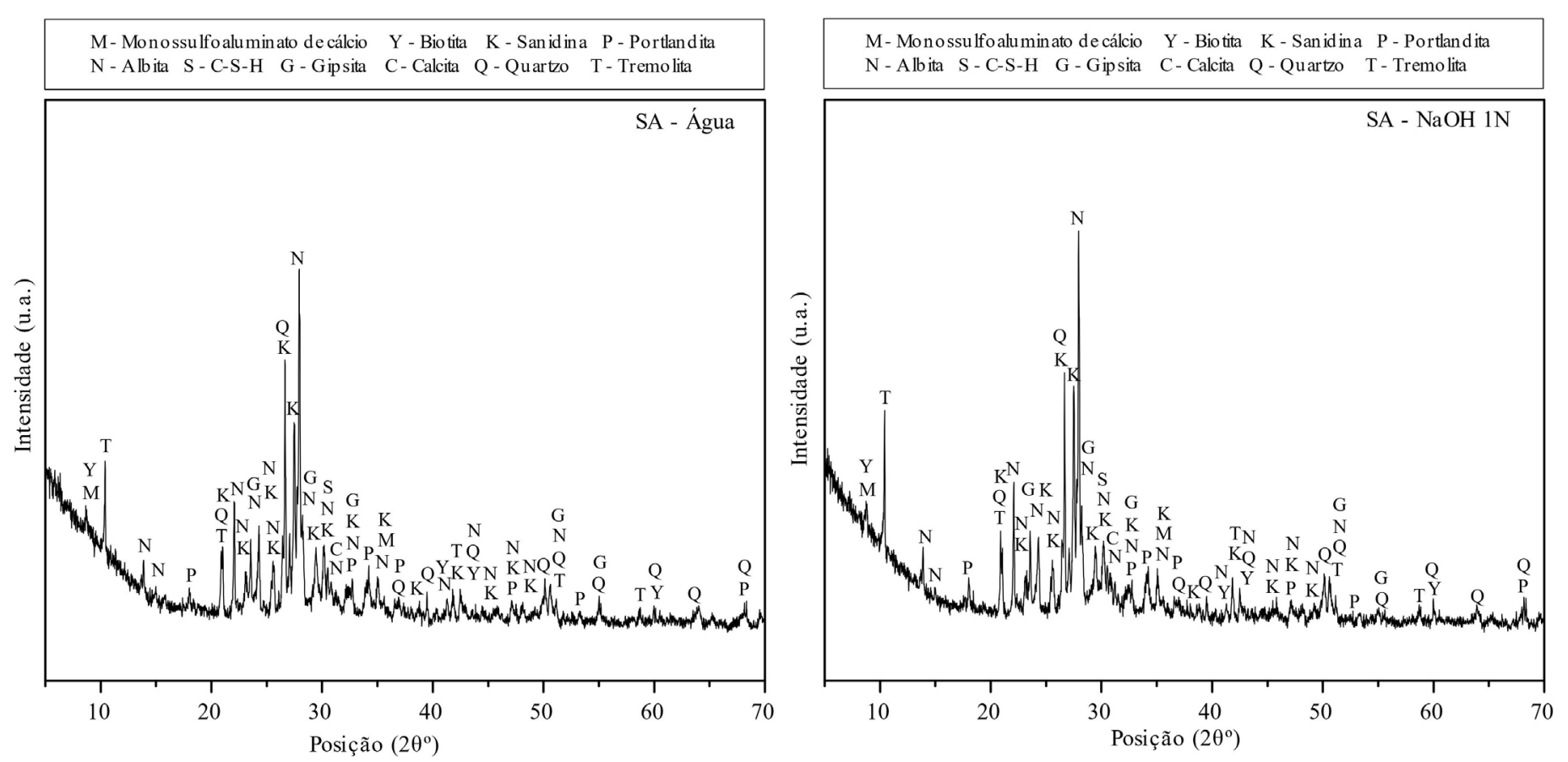

Fig. 9. Difratograma da série com sílica ativa em água destilada e solução de $\mathrm{NaOH} 1 \mathrm{~N}$.

O AMBT fornece uma fonte inesgotável de álcalis, pela solução de $\mathrm{NaOH}$, o que faz aumentar rapidamente a concentração alcalina nos poros e dessa forma, o desenvolvimento da RAS é acelerada.

A análise comparativa se deu referente aos picos de maior intensidade da sanidina $\left(27,46^{\circ} 2 \theta\right)$ e albita $\left(27,89{ }^{\circ} 2 \theta\right)$, devido ao uso do agregado. A sanidina $\left(\mathrm{KAISi}_{3} \mathrm{O}_{8}\right.$ ) e albita $\left(\mathrm{NaAlSi}_{3} \mathrm{O}_{8}\right.$ ) são apontadas como minerais que tendem a liberar álcalis podendo ser parcialmente consumidos na reação álcali- sílica (LNEC E 461, 2007). Desse modo, uma redução na quantidade deste composto poderia indicar ocorrência da RAS no sistema cimentício (BROEKMANS, 2012).

É possível observar que há uma pequena diminuição dos compostos referentes ao agregado (sanidina e albita) na série de referência submetida a solução de $\mathrm{NaOH}$, evidenciando que a condição do ensaio pode contribuir na dissolução dos álcalis disponíveis na argamassa. 
As Figuras 8 e 9 mostram os difratogramas das séries com cinza de casca de arroz e sílica ativa em ambas as condições (água destilada e solução de $\mathrm{NaOH}$ ). Assim como ocorreu na serie de referência, a Figura 8 mostra que a argamassa com CCA apresentou redução nos picos de sanidina e albina comparando o ensaio AMBT com a série em água. Por outro lado, a série com a SA (Figura 9) mostrou alteração na sanidina e albita, indicando a mitigação da RAS.

O pico principal relativo a portlandita $\left(34,1^{\circ} 2 \theta\right)$ para todas as amostras contendo as adições de sílica ativa e cinza de casca de arroz, foi inferior a série de referência, em ambas as condições de ensaio (água destilada e solução de $\mathrm{NaOH}$ ). $\mathrm{O}$ consumo da portlandita pode indicar que houve a reação pozolânica por parte das adições. Estudos realizados por Medeiros et al. (2017) apontaram resultados semelhantes para amostras de cimento Portland com adições e substituições parciais de metacaulim e sílica ativa quando comparadas ao cimento Portland CPV-ARI puro. A reação pozolânica dos adições minerais melhora a microestrutura das barras de argamassa, diminuindo a porosidade, a permeabilidade, levando a um material mais denso com melhores propriedades mecânicas e químicas, formando C-S-H pozolânico (produto estável), reduzindo o pH da solução de poros e contribuindo para limitar o dano causado pela RAS (AQUINO et al., 2001; HASPARYK et al., 2001; THOMAS et al., 2011; RÊGO et al., 2015; ABBAS et al., 2017).

Entretanto, mesmo que os resultados de DRX indiquem o consumo de portlandita devido à atividade pozolânica, as condições do ensaio AMBT podem ter atrapalhado o efetivo efeito das adições. De acordo com Thomas et al. (2007), as pozolanas reduzem a concentração de álcalis $(\mathrm{Na}+\mathrm{K})$ na solução dos poros em mais de 50\%. Porém quando há uma fonte inesgotável de álcalis, como é o caso da condição do ensaio, a pozolana retarda apenas o processo da RAS, impendindo inicialmente a entrada da solução, devido suas características e efeitos físicos (efeito fíller) e químicos (atividade pozolânica). Com o passar do tempo, os álcalis tendem a entrar em equilíbrio e a adição apenas serve como retardador da taxa de expansão.

\subsection{Análise termogravimétrica (TGA)}

Três principais faixas de perda de massa foram identificadas na análise de TG: primeira de 35 ${ }^{\circ} \mathrm{C}$ a $370{ }^{\circ} \mathrm{C}$, indicando o conteúdo de água quimicamente combinada com os hidratos, ou seja, decomposição de C-S-H, gipsita e etringita; segunda faixa de $370{ }^{\circ} \mathrm{C}$ a $525{ }^{\circ} \mathrm{C}$, água quimicamente ligada com o hidróxido de cálcio; e terceira faixa de $525^{\circ} \mathrm{C}$ a $1000{ }^{\circ} \mathrm{C}$, dióxido de carbono ligado com o carbonato de cálcio. A Figura 10 mostra a análise termogravimétrica das séries de referência, submetidas ao ensaio AMBT e também a mantida em água destilada.

A Tabela 3 mostra os resultados da análise termogravimétrica de todas as amostras. Para as amostras contendo adições minerais, o teor de portlandita remanescente foi menor que para a amostra de referência. O consumo é relacionado à reação pozolânica, corroborando os resultados semelhantes observados por autores como Kandasamy e Shehata, 2014; Abbas et al., 2017; Medeiros et al., 2017 e Hoppe Filho et al., 2017.

Quando se compara as amostras imersas em água destilada com as amostras imersas na solução de $\mathrm{NaOH}$, é também observado um decréscimo na quantidade de portlandita remanescente. Como as condições de ensaio propiciam a aceleração da reação álcali-sílica, da mesma forma, elas aceleram a reação pozolânica (LINDGARD et al., 2012).

A reatividade do material, o tamanho médio das partículas e a quantidade adicionada ao cimento são características importantes que influenciam no desenvolvimento da reação pozolânica. Lindgard et al. (2012) apontam em sua revisão, que em altas temperaturas, adições com partículas mais finas tendem a acelerar a reação pozolânica. Se comparada a curva granulométrica e o tamanho médio das partículas da sílica ativa e da cinza de casca de arroz (Figura 1) é possível justificar um dos pontos de desempenho, que contribuíram para a adição de sílica ativa ser mais eficiente no processo de inibição da RAS. A cinza de casca de arroz apresenta $D_{50}$ aproximadamente 32 vezes maior que $\circ D_{50}$ apresentado pela sílica ativa.

É bem conhecido que partículas menores 

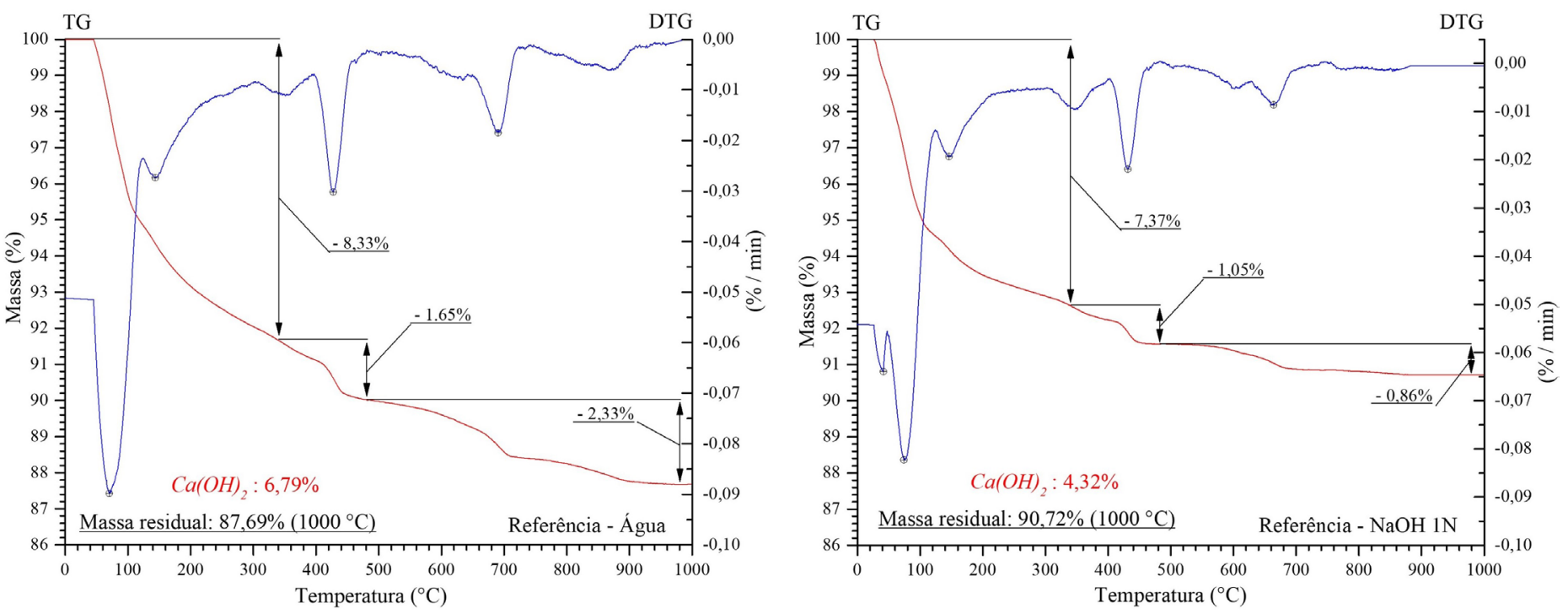

Fig. 10. TG e DTG das amostras de referência.

são capazes de reagir rapidamente devido à maior área de superfície, e isso tem importante influência no processo de hidratação e na cinética da RAS. Partículas CCA mais grossas diminuem a capacidade de empacotamento da mistura, levando a uma matriz ligeiramente mais porosa e permeável, facilitando a percolação de íons alcalinos. A moagem otimizada do material melhora as características pozolânicas aumentando a área superficial específica dos grãos (RÊGO et al., 2015). Segundo De Souza et al. (2000) as impurezas como compostos inorgânicos presentes na casca de arroz, não alteram significativamente a reação pozolânica, mas as partículas devem ter um tamanho pequeno na ordem de microns ou submicron. No mesmo contexto, Thanh et al. (2015), Ahsan e Hossain

Tabela 3. Análise termogravimétrica das amostras em água e submetidas ao ensaio AMBT.

\begin{tabular}{|c|c|c|c|c|c|}
\hline Amostra & $\begin{array}{c}\mathrm{C}-\mathrm{S}-\mathrm{H}+ \\
\text { aluminatos } \\
(\%)\end{array}$ & $\begin{array}{l}\mathrm{H}_{2} \mathrm{O} \\
(\%)\end{array}$ & $\begin{array}{c}\mathrm{Ca}(\mathrm{OH})_{2} \\
(\%)\end{array}$ & $\begin{array}{l}\mathrm{CO}_{2} \\
(\%)\end{array}$ & $\begin{array}{c}\mathrm{CaCO}_{3} \\
(\%)\end{array}$ \\
\hline $\begin{array}{l}\text { REF - } \\
\text { água }\end{array}$ & 8,33 & 1,65 & 6,79 & 2,33 & 5,30 \\
\hline $\begin{array}{l}\text { REF - } \\
\mathrm{NaOH}\end{array}$ & 7,37 & 1,05 & 4,32 & 0,86 & 1,95 \\
\hline $\begin{array}{l}\text { CCA - } \\
\text { água }\end{array}$ & 5,90 & 1,14 & 4,69 & 2,2 & 5,00 \\
\hline $\begin{array}{l}\mathrm{CCA}- \\
\mathrm{NaOH}\end{array}$ & 3,93 & 0,51 & 2,10 & 0,1 & 0,23 \\
\hline $\begin{array}{l}\text { SA - } \\
\text { água }\end{array}$ & 6,63 & 0,76 & 3,12 & 2,16 & 4,91 \\
\hline $\begin{array}{l}\mathrm{SA}- \\
\mathrm{NaOH}\end{array}$ & 3,51 & 0,09 & 0,37 & 0,32 & 0,73 \\
\hline
\end{tabular}

(2018) mostraram que as partículas de CCA mais finas são mais eficientes para mitigar a RAS do que as mais grossas. E quando se trata do AMBT, as condições do ensaio foram decisivas para o desempenho da adição mineral. Os resultados a seguir, de porosimetria por intrusão de mercúrio, serão úteis para ajudar a entender melhor esse comportamento.

\subsection{Porosimetria por intrusão de mercúrio}

A reação pozolânica não é o único ponto positivo do uso de adições para inibição da RAS. As adições minerais ativas podem contribuir para a redução da porosidade e permeabilidade de argamassas e concretos atuando também através do efeito físico, conhecido como efeito fíler. Esse efeito proporciona o refinamento dos poros da matriz, preenchimento de vazios com melhor empacotamento dos grãos além de contribuir para a nucleação heterogênea nos grãos de cimento (MOSER et al., 2010; AHSAN e HOSSAIN, 2018).

A reação álcali-sílica requer água para iniciar e, portanto, a redução na porosidade contribui para a mitigação do efeito da reação devido a alguns pontos importantes como a menor taxa de difusão de álcalis externos, diminuição da propagação de RAS e menor absorção de água pelo gel da RAS.

As condições agressivas do AMBT levam a considerar que as propriedades físicas das adições acabam tendo destaque no desempenho da 

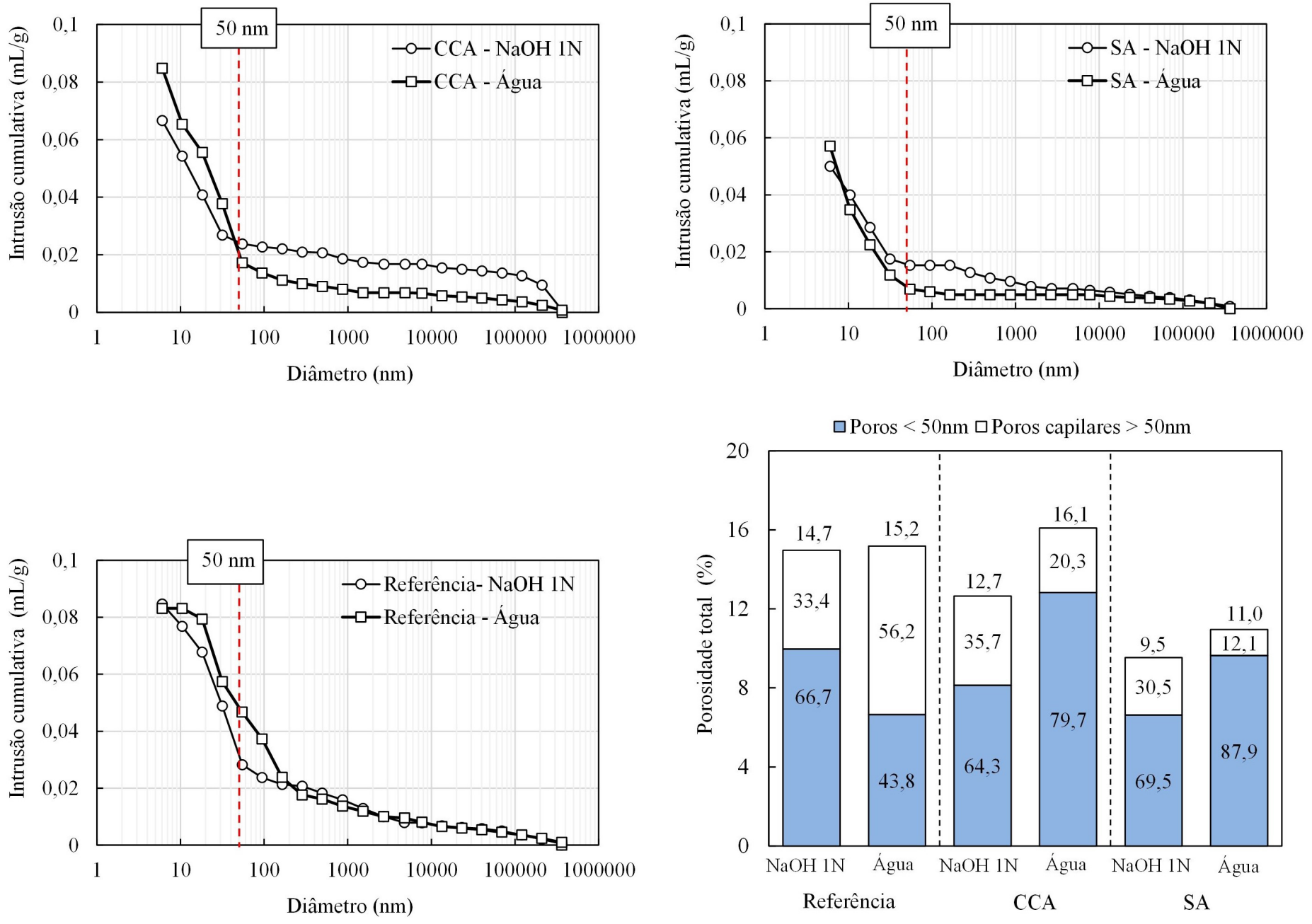

Fig. 11. Distribuição dos poros e porosidade total das amostras.

mesma frente a RAS, inclusive no desenvolvimento da reação pozolânica, como cita Lindgard et al. (2012).

A Figura 11 mostra a porosidade total e a distribuição do diâmetro de poros para todas as séries de argamassa, imersas na solução de $\mathrm{NaOH}$ a $(80 \pm 2){ }^{\circ} \mathrm{C}$ e também as imersas em água destilada e mantidas em temperatura ambiente (aproximadamente $24^{\circ} \mathrm{C}$ ).

É possível observar que a série de referência foi a única que apresentou um refinamento dos poros (poros menores que $50 \mathrm{~nm}$ ) quando as amostras foram submetidas ao ensaio AMBT. Observa-se também a redução da porosidade total quando, do mesmo modo que nas amostras contendo adição mineral. Isso pode ser justificado pela aceleração da hidratação do cimento devido as condições do ensaio.

Nas séries submetidas ao ensaio AMBT, as amostras com as adições apresentaram menor porosidade total e a partir desta porosidade e da observância da distribuição dos poros, a sílica ativa foi a adição que apresentou um maior refinamento dos poros da matriz. Se destacada a elevada temperatura do AMBT, é possível entender a aceleração da reação pozolânica nas barras com as adições. A porosidade total teve um decréscimo, porém na distribuição do diâmetro dos poros é possível obervar que o efeito químico foi rápido demais não proporcionando um refinamento dos poros. É notável o efeito da reação pozolânica nas amostras em água destilada, que apesar das amostras apresentarem uma porosidade total um pouco mais elevada, houve um refinamento dos poros notável em ambas as argamassas com adições minerais.

Além da menor porosidade, a argamassa com substituição parcial do cimento por sílica ativa apresentou também o menor coeficiente de permeabilidade (Figura 12). 


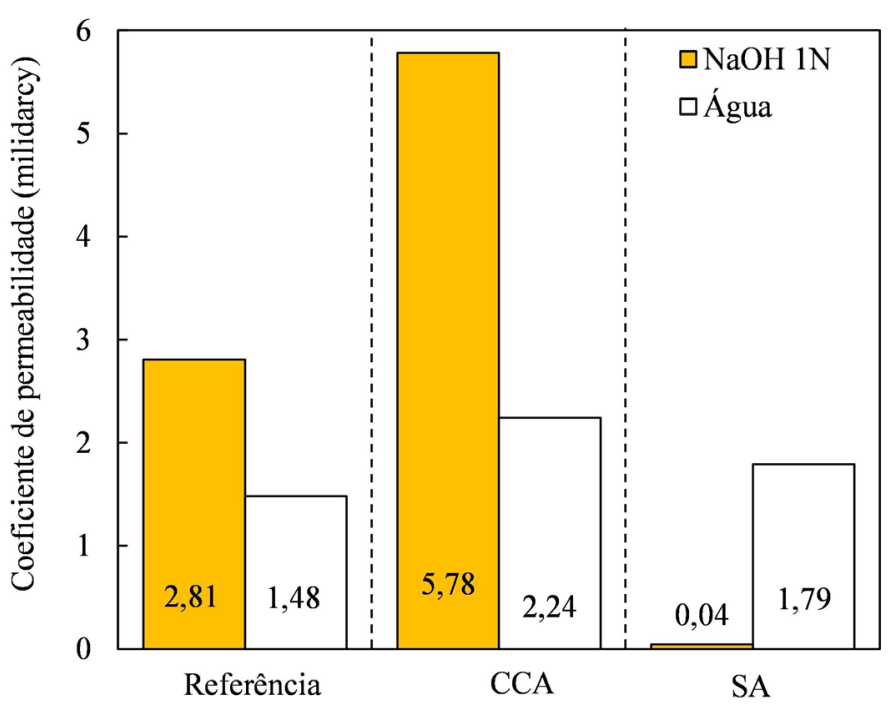

Fig. 12. Permeabilidade das argamassas.

Os resultados obtidos para a sílica ativa corroboram com os resultados dos demais testes, mostrando menor coeficiente de permeabilidade, menor porosidade total e menor expansão das barras de argamassa (AMBT).

A argamassa contendo CCA apresentou um coeficiente de permeabilidade maior que os demais (ou seja, SA e referência). A cinza de casca de arroz foi capaz de reduzir a porosidade total quando submetida ao teste (comparando a série em água destilada), principalmente devido a aceleração da reação pozolânica. Os produtos secundários formados com a reação pozolânica ajudam a preencher alguns vazios e o espaçamento interpartículas, o que explica a menor porosidade. Mas, mesmo considerando a reatividade e a formação do C-S-Hpozolânico, a cinza de casca de arroz não foi capaz de acessar totalmente os vazios mais finos e reduzir a permeabilidade das barras de argamassa. A distribuição dos diâmetros dos poros mostrou que $66,7 \%$ dos poros das amostras de referência foram menores que $50 \mathrm{~nm}$ (microporos), enquanto na argamassa com sílica ativa foi de $69,5 \%$ e com cinza de casca de arroz foi de $64,3 \%$ dos poros.

Ahsan e Hossain (2018) observaram que cinzas de casca de arroz com partículas mais grossas contribuíram significativamente na expansão devido a RAS. As partículas grossas criam uma distância entre elas devido a uma não homogeneização na mistura o que contribui para o ingresso de agentes externos, no caso da solução de $\mathrm{NaOH}$, e água.

Já a sílica ativa foi capaz de alterar significativamente a microestrutura das argamassas devido a sua morfologia, composição química e reatividade, considerando essencialmente a avaliação de curto prazo do ensaio, como o teste acelerado de barras de argamassa. Os resultados para a expansão induzida foram significativamente diferentes o que pode indicar que as propriedades químicas e principalmente físicas (granulometria) das adições minerais ativas são importantes no controle da cinética da RAS para a avaliação de curto prazo em ambiente agressivo, como é o caso do AMBT. Além disso, é necessário considerar que o ensaio AMBT pôde não proporcionar condições ideais para o desenvolvimento da reação pozolânica uma vez que existe uma fonte inesgotável de álcalis e, portanto, as adições minerais não devem ser descartadas apenas a partir dos resultados obtidos por este teste. Testes em concreto e em campo devem ser considerados.

\section{Conclusões}

Este trabalho experimental permite estabelecer as conclusões a seguir:

O efeito da elevada temperatura e da solução de $\mathrm{NaOH}$ no desenvolvimento da reação pozolânica, refinamento dos poros e redução da permeabilidade das argamassas por parte das adições minerais ativas, pôde ser observado.

Os resultados de expansão mostraram que as argamassas com sílica ativa e com a cinza de casca de arroz foram capazes de diminuir a taxa de expansão da RAS, em comparação com as amostras de referência. O ensaio pelo método acelerado demonstrou que a adição de $10 \%$ de sílica ativa como substituição parcial do cimento foi a opção mais efetiva em mitigar a reação álcali-sílica. A minimização da expansão está relacionada à redução do teor de hidróxido de cálcio na argamassa, corroborando com a maior atividade pozolânica apresentada pela sílica ativa no ensaio Chapelle modificado.A porosidade e a permeabilidade das amostras estão relacionadas diretamente com a finura das partículas, seja pela ação física 
de empacotamento, como pela ação química de atividade pozolânica, desta forma, a maior área de superfície influência no processo de hidratação e na cinética das reações. Consequentemente, partículas mais grossas diminuem a capacidade de empacotamento da mistura, levando a uma matriz ligeiramente mais porosa e permeável, conforme observado na comparação entre as amostras.

O AMBT não proporcionou conclusões exatas sobre o uso da cinza de casca de arroz como material inibidor da RAS para uso em conjunto do cimento. As propriedades físicas do material, como granulometria e diâmetro médio das partículas foram primordiais no desempenho dessa adição frente a reação deletéria no teste acelerado, necessitando de testes específicos para cada caso de aplicação.

Outros estudos são propostos com a cinza de casca de arroz, principalmente testes em concreto, visto que há poucas pesquisas ainda na literatura com o uso desse material e muitas são contraditórias. Não se deve descartar o uso de um potencial material com base em apenas um ensaio acelerado. Entender os mecanismos por trás do teste são necessários para classificar uma adição como potencial inibidora da reação álcali-sílica.

\section{Agradecimentos}

Os autores agradecem ao Programa de PósGraduação em Engenharia de Construção Civil da Universidade Federal do Paraná e o suporte financeiro promovido pela CAPES (Coordenação de Aperfeiçoamento de Pessoal de Nível Superior).

\section{Referências Bibliográficas}

ABBAS, S.; KAZMI, S. M. S.; MUNIR, M. J. Potential of rice husk ash for mitigating the alkali-silica reaction in mortar bars incorporating reactive aggregates. Construction and Building Materials, v. 132, p. 61-70, 2017.

AHSAN, M. B.; HOSSAIN, Z. Supplemental use of rice husk ash (RHA) as a cementitious material in concrete industry. Construction and Building
Materials, v. 178, p. 1-9, 2018.

ALAEJOS, P.; LANZA, V.; BERMÚDEZ, M. A.; VELASCO, A. Effectiveness of the accelerated mortar bar test to detect rapid reactive aggregates (including their pessimum content) and slowly reactive aggregates. Cement and Concrete Research, v. 58, p. 13-19, 2014

AMERICAN SOCIETY FOR TESTING AND MATERIALS. ASTM C150, Standard Specification for Portland Cement, ASTM International, West Conshohocken, PA, 2020.

AMERICAN SOCIETY FOR TESTING AND MATERIALS. ASTM C294, Standard Descriptive Nomenclature for Constituents of Concrete Aggregates, ASTM International, West Conshohocken, PA, 2019.

AMERICAN SOCIETY FOR TESTING AND MATERIALS. ASTM C1260-14, Standard Test Method for Potential Alkali Reactivity of Aggregates (Mortar-Bar Method), ASTM International, West Conshohocken, PA, 2014.

AQUINO, W.; LANGE, D.; OLEK, J. The influence of metakaolin and silica fume on the chemistry of alkali-silica reaction products. Cement and Concrete Composites, v. 23, n. 6, p. 485-493, 2001.

ASOCIACIÓN ESPAÑOLA DE NORMALIZACIÓN Y CERTIFICACIÓN. UNE-EN 197-1, Cementos comunes: deficiones, denominaciones, classificacción y especificaciones de los mismos. 2011.

ASOCIACIÓN ESPAÑOLA DE NORMALIZACIÓN Y CERTIFICACIÓN. UNE 146508, Determinación de la reactividad potencial álcali-sílice y álcali-silicato de los áridos. Método acelerado en probetas de mortero. 2018.

ASSOCIAÇÃO BRASILEIRA DE NORMAS TÉCNICAS. ABNT NBR 15895-10, Materiais pozolânicos Determinação do teor de hidróxido de cálcio fixado - Método Chapelle modificado. Rio de Janeiro: ABNT, 2010.

ASSOCIAÇÃO BRASILEIRA DE NORMAS TÉCNICAS. 
ABNT NBR 15577-1: Agregados - Reatividade álcali-agregado Parte 1: Guia para avaliação da reatividade potencial e medidas preventivas para uso de agregados em concreto. Rio de Janeiro: ABNT, 2018.

ASSOCIAÇÃO BRASILEIRA DE NORMAS TÉCNICAS. ABNT NBR 15577-4: Agregados - Reatividade álcaliagregado Parte 4: Determinação da expansão em barras de argamassa pelo método acelerado. Rio de Janeiro: ABNT, 2018.

ASSOCIAÇÃO BRASILEIRA DE NORMAS TÉCNICAS. ABNT NBR 15577-5: Agregados - Reatividade álcaliagregado Parte 5: Determinação da mitigação da expansão em barras de argamassa pelo método acelerado. Rio de Janeiro: ABNT, 2018.

BROEKMANS, M. A. T. M. Deleterious reactions of aggregate with alkalis in concrete. Reviews in Mineralogy and Geochemistry, v. 74, n. 1, p. 279364, 2012.

Canadian Standards Association. CAN/CSA-A23.225A-14, Test method for detection of alkali-silica reactive aggregate by accelerated expansion of mortar bars. 2014.

CONSTANTINER, D.; DIAMOND, S. Alkali release from feldspars into pore solutions. Cement and Concrete Research, v. 33, n. 4, p. 549-554, 2003.

CORDEIRO, G. C. et al. Influence of particle size and specific surface area on the pozzolanic activity of residual rice husk ash. Cement and Concrete Composites, v. 33, n. 5, p. 529-534, 2011.

DESCHENES, R. A.; MICAH HALE, W. AlkaliSilica Reaction in Concrete with Previously Inert Aggregates. Journal of Performance of Constructed Facilities, v. 31, n. 2, p. 04016084 , 2017.

FOURNIER, B.; BÉRUBÉ, M.-A. Alkali-aggregate reaction in concrete: a review of basic concepts and engineering implications. Canadian Journal of Civil Engineering, v. 27, n. 2, p. 167-191, 2000.
FOURNIER,B. et al. Evaluating Potential AlkaliReactivity of Concrete Aggregates - How Reliable are the Current and New Test Methods? In: II SYMPOSIUM ON ALKALI-AGGREGATE REACTION IN CONCRETE STRUCTURES, 2006. Rio de Janeiro. Anais [...]. São Paulo: IBRACON, 2006

GOLMAKANI, F.; HOOTON, R. D. Comparison of laboratory performance tests used to assess alkalisilica reactivity. Proceedings, Annual Conference Canadian Society for Civil Engineering, v. 2, p. 1-7, 2016.

HASPARYK, N. P.; MONTEIRO, P. J. M.; CARASEK, H. Effect of Silica Fume and Rice Husk Ash on AlkaliSilica Reaction. ACI Materials Journal, n. 97, 2001.

HOPPE FILHO, J. et al. Reactivity assessment of residual rice-husk ashes. Journal of Materials in Civil Engineering, v. 29, n. 6, p. 04017003, 2017

KANDASAMY, S.; SHEHATA, M. H. The capacity of ternary blends containing slag and high-calcium fly ash to mitigate alkali silica reaction. Cement and Concrete Composites, v. 49, p. 92-99, 2014.

KATZ, A. J.; THOMPSON, A. H. Quantitative prediction of permeability in porous rock. Physical Review B, v. 34, n. 11, p. 8179-8181, 1986.

LATIFEE, E. R.; RANGARAJU, P. R. Miniature concrete prism test: Rapid test method for evaluating alkalisilica reactivity of aggregates. Journal of Materials in Civil Engineering, v. 27, n. 7, 2015.

LINDGARD, J. et al. Alkali-silica reactions (ASR): Literature review on parameters influencing laboratory performance testing. Cement and Concrete Research, v. 42, n. 2, p. 223-243, 2012.

LNEC E 461. Betões. Metodologia para prevenir reacções expansivas internas, 2007. Lisboa.

LOCATI, F.; MARFIL, S.; BALDO, E. Effect of ductile deformation of quartz-bearing rocks on the alkalisilica reaction. Engineering Geology, v. 116, n. 1, p. 117-128, 2010. 
MEDEIROS, M. H. F. DE; RAISDORFER, J. W.; HOPPE FILHO, J. Influência da sílica ativa e do metacaulim na velocidade de carbonatação do concreto: relação com resistência, absorção e relação a/c. Ambiente Construído, v. 17, n. 4, p. 125-139, 2017.

MEDEIROS, M. H. F. DE; RAISDORFER, J. W.; HOPPE FILHO, J.; MEDEIROS-JUNIOR, R. A. Partial replacement and addition of fly ash in Portland cement: influences on carbonation and alkaline reserve. Journal of Building Pathology and Rehabilitation, v. 2, n. 1, p. 4, 2017.

QUARCIONI, V. A.; CHOTOLI, F. F.; COELHO, A. C. V.; CINCOTTO, M. A. Indirect and direct Chapelle's methods for the determination of lime consumption in pozzolanic materials. IBRACON Structures and Materials Journal, v. 8, n. 1, p. 1-7, 2015.

RÊGO, J. H. S.; NEPOMUCENO, A. A.; FIGUEIREDO, E. P.; HASPARYK, N. P. Microstructure of cement pastes with residual rice husk ash of low amorphous silica content. Construction and Building Materials, v. 80, p. 56-68, 2015.

SHEHATA, M. H.; THOMAS, M. D. A. The effect of fly ash composition on the expansionof concrete due to alkali-silica reaction. Cement and Concrete Research, v. 30, n. 7,p. 1063-1072, 2000

DE SOUZA, M. F. et al. al. al. Rice hull-derived silica: applications in Portland cement and mullite whiskers. Materials Research, v. 3, n. 2, p. 25-30, 2000.

THANH, H.; SIEWERT, K.; LUDWIG, H. Alkali silica reaction in mortar formulated from self-compacting high performance concrete containing rice husk ash. Construction and Building Materials, v. 88, p. 10-19, 2015.

THOMAS, M. The effect of supplementary cementing materials on alkali-silica reaction: A review. Cement and Concrete Research, v. 41, n. 12, p. 1224-1231, 2011. evaluating supplementary cementing materials using accelerated mortar bar test. ACI Materials Journal, v. 104, n. 2, p. 115-122, 2007.

THOMAS, M. D. A.; FOLLIARD, K. J. Concrete aggregates and the durability of concrete. C.L. Page, M.M. Page (Eds.), Durability of concrete and cement composites, Woodhead, Cambridge, U.K, p. 247-281, 2007.

THOMAS, M.; DUNSTER, A.; NIXON, P.; BLACKWELL, $B$. Effect of fly ash on the expansion of concrete due to alkali-silica reaction - Exposure site studies. Cement and Concrete Composites, v. 33, n. 3, p. 359-367, 2011.

THOMAS, M. et al. Test methods for evaluating preventive measures for controlling expansion due to alkali-silica reaction in concrete. Cement and Concrete Research, v. 36, n. 10, p. 1842-1856, 2006.

VALDUGA, L. Influência das condições de ensaio da ASTM C 1260 na verificação da reação álcaliagregado. 204 f. Tese (Doutorado em Engenharia Civil) - Universidade Federal do Rio Grande do Sul, 2007 